\title{
LA CITÉ DES DAMESE O TRIUNFO DAS MULHERES DE CHRISTINE DE PIZAN: ASPECTOS DE UMA CIDADE FEMININA FUNDADA NA DEMOLIÇÃO DO LEGADO DA MISOGINIA MEDIEVAL
}

\section{LA CITÉ DES DAMESAND THE TRIUMPH OF CHRISTINE DE PIZAN' WOMEN: ASPECTS OF A FEMALE CITY FOUNDED IN THE DEMOLITION OF THE LEGACY OF MEDIEVAL MISOGYNY}

\section{RESUMO}

Pelo viés da leitura intertextual, este artigo pretende questionar e refletir sobre a ideia de cidade em $A$ cidade das Damas, de autoria de Christine de Pizan, idealizada em 1405, com o propósito de dialogar sobre construção dessa cidade feminina a partir de uma leitura crítica ressignificante das realidades das mulheres expostas pela ideologia da misoginia medieval. Para tanto, serão identificados e discutidos alguns temas e questões pertinentes à visão misógina dos representantes desse gênero de literatura medieval, cujos pronunciamentos antifemininos acham-se presentes no livro de Christine de Pizan. A principal contribuição do seu texto consiste na originalidade temporã de sua autora em argumentar e propor a construção de uma cidade favorável à ideia de inclusão e diálogo de e para mulheres. Trata-se de uma cidade engendrada para promover, através do seu exemplo, a emancipação das mulheres do jugo misógino da tradicional visão masculina. Nesse sentido, pioneira e adventícia para a sua época, a metáfora da construção em A Cidade das Damas de Christine de Pizan, dá um novo sentido ao arcano simbolismo da tessitura feminina de lastro misógino, para propor uma tomada de consciência da condição histórica e cultural das mulheres, naqueles tempos de robustas adaptações literárias vernaculares do legado da misoginia na tardia Idade Média. Mutatis mutandis, não fosse a questão de propriedade epistemológica, Christine de Pizan já teria sido, no final da Idade Média, uma voz de decolonialidade do discurso misógino hegemônico, caso, como se verá, ela não tivesse reproduzido, no seu discurso, maneiras e modos de ser do tradicional discurso da colonialidade das mulheres.

Palavras-chave: Literatura medieval. Misoginia. Ressignicação. Adaptações vernaculares. Christine de Pizan. A Cidade das Damas.

\begin{abstract}
From the perspective of an intertextual reading, this article aims to question and reflect about the idea of city in The City of Ladies, by Christine de Pizan, idealized in 1405. The purpose is to discuss the construction of this female city through a critical reading that gives a new meaning to the realities of women exposed by the ideology of the medieval misogyny. To this end, some themes and issues pertinent to views of representatives male figures of this medieval misogynist literary genre will
\end{abstract}

Pedro Carlos Louzada Fonseca

Universidade Federal de Goiás (UFG). Email: pfonseca@globo.com 
be identified and discussed whose antifeminine pronouncements are present in the book. The article discusses as Christine de Pizan's main contribution her originality in arguing and proposing the construction of a city favorable to the idea of inclusion and dialogue by and for women. It is a city designed to promote, through its example, the emancipation of women from the misogynistic yoke of the traditional male views. In this sense, pioneering and adventitious for its time, the metaphorical construction of Christine de Pizan's City of Ladies resignifies the arcane symbolism of the female weaving of misogynistic shape to propose a possible female consciousness of the historical and cultural conditions of the women in those times of robust vernacular adaptations of the legacy of misogyny in the late literary Middle Ages. Mutatis mutandis, had it not been for the question of epistemological property, Christine de Pizan would have been, at the end of the Middle Ages, a voice of decoloniality of the hegemonic misogynistic discourse, if, as it will be seen, she had not reproduced in her discourse traditional ways and forms of being of the traditional discourse of the coloniality of women.

Keywords: Medieval literature. Misogyny. Resignifications. Vernacular adaptations. Christine de Pizan. The City of Ladies.

As mulheres, quer difamadas ou defendidas na tradição literária medieval, não parecem ter sido objeto de interesse e tratamento históricos a exemplo da atenção dada às histórias dos homens. À parte as múltiplas possibilidades e hipóteses investigadoras dessa situação, pode-se mesmo seguramente concluir, como julgamento desse assunto, o fato de que as mulheres foram essencializadas pela nãopossibilidade de participarem como agentes das histórias de si próprias, quanto mais das histórias dos homens. E, de modo lacônico, mas perfeitamente nos limites de uma proposição crítica, pode-se dizer ainda que as mulheres não tiveram histórias próprias por causa da propriedade eterna da política androcêntrica que também sofreu, entretanto, beneficamente, um processo essencialista.

Ainda que nos limites dessas sintéticas tomadas reflexivas sobre a questão de participação e pertencimento das mulheres nas várias sociedades e culturas em que tiveram as suas realidades e existências inseridas, o cenário dessa problemática, na Idade Média Ocidental, é extremamente instigante. Ele abrange centenas de séculos desenvolvendo representações e textos fundamentais concernentes à visão sobre as mulheres polarizadas, ora em situações de elogio e defesa, ora de difamação e ataque, cujas razões antropológicas constituem um fértil terreno para investigações.

Apresentadas as preliminares anteriores, e com base nas reflexões nelas propostas, este estudo sobre a dialogia da construção de A Cidade das Damas de Christine de Pizan, examina o intrigante livro homônimo dessa notável intelectual medieval, figura não menos fascinante pelo seu temporão desempenho profeminino na sua época, o final da Idade Média, tempos em que o rescaldo de uma tradicional misoginia de ranço teológico da literatura dos Padres da Igreja, curiosamente, tendia a superimpor à mulher, simplesmente má do arcano passado histórico, mitológico 
e bíblico, a imagem da mulher diabolizada do final da Idade Média e princípios dos tempos modernos. Há, entretanto, explicações suficientemente fundamantais para a análise desse novo estado de coisas (FONSECA, 2017, p. 13-52; 2020, p. 1-36).

Como nada nas mentalidades e nas formações culturais dos indivíduos e das sociedades nascem simplemente num vacuum, principalmente em sociedades como a medieval, fortemente marcada por condicionalismos políticos e ideológicos, a proposta de se estudar, neste artigo, a contribuição literária de Christine de Pizan, enfocada no livro Le Livre de la Cité des Dames (1405), como repositório temático da construção de um espaço utópico em analogia com um diálogo disfórico da misoginia medieval, necessita de contextualização. Talvez o principal motivo dessa contextualização tenha a ver com a grande fascinação que os medievais tiveram pelo imaginário de uma cidade devidamente protegida e que abrigasse não só física, mas, principalmente, moral e espiritualmente, os seus habitantes, conforme se exemplicará a seguir. Nesse sentido, é de se constatar que a "resposta" de cidade de Christine de Pizan é uma espécie de resposta que corresponde, no próprio contexto medieval, a um terceiro tipo de cidade, uma vez que Santo Agostinho já tinha respondido com as virtudes e salvação da sua cidade teológica aos vícios e perdições de muitas cidades imorais dos homens, a exemplo de Babel, Sodoma e Gomorra.

A Cidade das Damas, de Christine de Pizan, é um verdadeiro exercício do gênero moralidade, constante da dramaturgia medieval, cujo recurso figurativo de grande efeito dialógico são as chamadas dramatis personae, ou seja, alegorias cunhadas para personificar as três damas interlocutoras de Christine no processo de construção textual, ético e moral da sua cidade. Essas damas são as Senhoras Razão, Retidão e Justiça, significando que os assuntos serão discutidos buscandose o entendimento lógico, acertado e justo, predicados que a misoginia medieval jamais julgou de competência feminina. É uma construção de grande originalidade ideológica e política considerando-se o conhecimento e o alcance de uma mulher da sua época. Outro contraponto conceitual da figura da cidade em Christine de Pizan encontra-se no grande repertório das tradicionais cidades, históricas ou mitológicas, ou de espaços engendrados no feminino. Desde a barbárie do migratório espaço das amazonas até a fundação das regiões ou espaços culturais do que veio a ser própria Europa, sob a égide de célebres mulheres, uma parada de cidades memoráveis se registra.

Ingênua euforia à parte por esse pseudo triunfalismo, porque faz parte de uma construção alienante sob a égide apenas do empreendedor, a feminização de geografias ou espaços de conquista androcêntrica é uma violência simbólica de um discurso colonizador da cultura masculina que decreta prerrogativas de naturalização com toda uma litania semântica de conceitos fundamentais ao entendimento daquela tropologia, quais sejam, o reducionismo e o essencialismo subserviente de realidades que ambiciona conquistar e dominar.

Espaços e geografias femininas bárbaras ou refinadamente culturais como a Cidade das Damas, apesar de suas propostas entusiasmadas, nem sempre percebem certa utopia na legitimidade de sua origem, pois o paradigma ou modelo de cidade, 
mesmo construída por mulheres, ainda é falogocêntrico, cujas formas de auctoritas incontestáveis vêm de um modelo aristotélico nascido no Mar Egeu, onde tudo começou, palco de uma profusa malha épica sinonimizada ao masculino.

Diante desse panteão de histórias e cidades dos homens, no seu contexto literário e cultural do final da Idade Média, já com as suas cosmovisões sedimentadas por um inteiro milênio, com todo esse peso cultural de uma hegemonia patriarcal significada e ressignificada desde a antiga Lei, contra quem ergem-se os muros e as vozes das damas de A Cidade das Damas de Christine de Pizan, exímia arquiteta a dirigir a construção de uma cidade, cuja realização, como gênero feminino, depende da deposição da cultura antifeminina da misoginia medieval.

É com esse cenário desafiador que Christine de Pizan e suas damas interagem dialogicamente e desse processo discursivo resultará a construção da sua cidade, portanto, uma construção textual auxiliada por processos metalinguísticos e epistemológicos. Sobretudo, essa construção foi empreendida para ser defensiva. Mas em que consistem os estratagemas dessa defesa? Simplesmente na elaboração de uma justificativa que é um discurso deponente, uma das mais poderosas formas de melhor se auferir poder, uma vez que é de outro discurso de poder hegemônico que se pretende ganhar, qual seja, o discurso da misoginia medieval, contra o qual se bate em busca de uma desconstrução disfórica para o lado androcêntrico, eufórica para o lado ginocêntrico.

Principalmente, devido à metodologia dialógica que o trato deste problema favorece, deve-se considerar qual é o intertexto com o qual Christine de Pizan dialoga em sua Cidade. Esse diálogo na verdade encerra um jogo antitético de imagens temáticas ligadas ao sentido de construção verbal dessa cidade, na medida em que a sua euforia construtora significa a própria disforia da desconstrução de tradicionais discursos antológicos da difamação das mulheres. Esse diálogo desconstrutor de $A$ Cidade das Damas é com o contexto misógino da literatura medieval, com toda a tradição antifeminina nas suas bases fundadoras.

Com raízes fincadas na Antiguidade Clássica e nas Escrituras Sagradas judaico-cristãs, essa tradição misógina se representa pelos escritos dos Padres da Igreja também chamados patristas, e do seu legado medieval, passando pela tradição satírica, no latim medieval, até culmninar com as chamadas adaptações vernaculares dessa herança misógina na Idade Média tardia.

Christine de Pizan (1363 - c. 1430) pode ser considerada como uma das mais significativas vozes de uma incipiente e moderna reação à misoginia medieval surgida ainda na tardia Idade Média, embora nela haja indícios de comprometimento com ideais conservadores e latentes relativos ao decoro feminino (GOTTLIEB, 1990, p. 88-103), talvez reflexo da tentativa de sua mãe em moldá-la convencionalmente em tarefas femininas. Entretanto, graças a incentivos de seu pai e de seu marido, Christine de Pizan desenvolveu os seus dotes intelectuais e talento literário, legando à posteridade uma vasta produção que abrangeu cerca de quarenta anos. Ela nasceu na Itália, mas cresceu no convívio com círculos culturais na corte de Carlos V da França. 
Casada aos quinze anos, Christine cumpriu o ritual patriarcalista dos casamentos femininos precoces, quando o investimento era um custo visando ao benefício que uma esposa deveria dar. Mas Christine de Pizan teve a sorte de o seu marido apoiá-la no desenvolvimento dos seus talentos literários, o que lhe valeu a sobrevivência quando faleceram o pai e o marido, depois de 1389 , tendo que custear sozinha três crianças. A carreira literária de Christine de Pizan tornou-se notável por uma imensidade de temas tratados, muitos em posição crítica aos tratamentos dados às mulheres pelos homens e suas intituições. Entretanto, uma apressado leitura em advogar a Christine de Pizan um protofeminismo tem que ser melhor avaliado porque, conforme será visto mais adiante, ela ainda, por força dos tempos, submete-se, com reserva, aos condicionalismos da cultura patriarcal de sua época, preocupada com questões que refletem um ideal decoro feminino. Na verdade, Christine de Pizan, ao argumentar abertamente em defesa da mulher, foi realmente baluarte, pioneira e original, visto que, apesar de diminuta esse tipo de escrita já circulava em autoria anônima ou mesmo masculina, na época em que foi escrita A Cidade das Damas.

Christine de Pizan não defendeu as mulheres apenas em A Cidade das Damas. Essa disposição temática, com suas nuances argumentativas, já comparece, não menos importantemente configurada, em L'Epistre au Dieu D’Amouus escrita em 1399. Se em A Cidade das Damas a alegoria indica traços do ambiente de tratamento cortês, em Carta ao Deus do Amor, com sugestões mitológicas da cultura clássica, Christine de Pizan recria um Deus do Amor contraposto à sua clássica entidade venérea, Vênus, a Deusa do Amor.

É realmente surpreendente o espírito de desconstrução da oficialidade misógina que Christine de Pizan apresenta como crítica. Entretanto, sempre a sua defesa das mulheres ainda se prende a uma certa obediência ao paradigma masculino. A bem da verdade, os tempos em que Christine de Pizan viveu já começavam a exigir que as pessoas começassem a desmantelar o dogma misógino, para além do maniqueísta jogo do bem e do mal trazidos pela mulher.

Na sua reação antimisógina, Christine de Pizan recebeu influência, sem, entretanto, dar os devidos créditos, de Le Livre de Leesce (O livro de Leesce), de Jehan Le Fèvre, uma pretensa. mas suspeita refutação às alegações misóginas contidas em Les Lamentations de Matheolus (As lamentações de Mateolus), do mesmo autor, ambos escritos na segunda metade do século XIV (LE FÈVRE, 1892-1905).

Apesar de se basear em fontes e referências precedentes apologéticas da mulher, o propósito de Christine de Pizan, em redefinir o perfil feminino tradicional, foi bastante importante por ter entendido as forças motrizes do pensamento misógino antigo e medieval. Ela viu, com grande clareza, a terrível internalização, por parte das mulheres, de uma injustificável desvalorização de seu sexo e de sua mente. E mais, entendeu, com uma visão bastante adiantada para a sua época, que a única maneira para um bem sucedido desafio à misoginia implicava em desmoralizar a idoneidade de prestigiosas autoridades intelectuais e literárias masculinas do mundo clássico, da patrística e da vernaculidade medieval. Em sua visão defensora da mulher tem sido argumentado que Christine de Pizan não é suficientemente antitética 
na refutação das discriminações misóginas, por não fazer uso convincentemente retórico da contra-argumentação aos lugares-comuns apresentados. Não obstante a isso, ela desmantela cânones da misoginia de forma retoricamente racional e inteligentemente apelativa, em defesa da mulher secularmente escorraçada por um androcentrismo politicamente impiedoso.

Entretanto, não só em A Cidade das Damas, Christine de Pizan elabora a contrapelo a sua crítica de denúncia da misoginia. Trazendo o formato de uma declaração, o poema Carta ao Deus do Amor, de Christine de Pizan, tem o formato de um documento público que contêm veementes reclamações endereçadas à Corte dessa divindade por multidões de mulheres, referentes aos desmandos dos seus falsos amantes, protestando, principalmente, contra as difamações surgidas das conversas casuais dos homens sobre suas conquistas sexuais, eles que, supostamente, deveriam ser os guardiões da honra das mulheres.

Ao mesmo tempo em que Christine de Pizan estava escrevendo A Cidade das Damas, ela se havia tornado uma figura fundamental no debate literário sobre o valor moral de Le Roman de la Rose (O romance da Rosa, debate esse que ficou conhecido por Querelle de la Rose - c. 1400-c. 1403 - Querela da Rosa). Dignitários da Corte e da Igreja tomaram seus partidos, uns defendendo a Rosa e outros apoiando Christine de Pizan no seu repúdio ao poema de Jean de Meun. Os pontos em referência misógina do poema, sistematicamente denunciados por Christine de Pizan estão na parte de Jean de Meun censurada por seu sensacionalismo dissoluto, uso indecente de linguagem, condescendência a comportamentos imorais, sempre em se tratando do caráter e da conduta feminina.

É nesse sentido revisionista das posturas misóginas, num procedimento dialético de construir/desconstruindo, que Christine de Pizan constrói o seu polêmico Le Livre de la Cité des Dames. Portanto, conforme sugerido anteriormente, mais do que uma semelhança à ostensiva Cidade de Deus, de Santo Agostinho, A Cidade das Damas é uma construção defensiva. É construída sobre a reputação de mulheres, histórica e lendariamente, conspícuas em todo o campo de empreendimento ou moralidade, sendo uma verdadeira fortaleza para oferecer proteção ao sexo discriminatoriamente inferiorizado.

Na construção da escrita antimisógina de seu Le Livre de la Cité des Dames, Christine de Pizan baseia-se ainda, de forma bastante extensiva, no livro intitulado De mulieribus claris (Sobre as mulheres famosas), de Giovanni Boccaccio, primeiramente publicado em 1374 (BOCCACCIO, 1964). Entretanto, no decorrer do presente artigo, poucos exemplos dessas famosas mulheres boccaccianas são citados, porque parece de maior prioridade representar, tão completamente quanto possível, a moldura que tais exemplos ilustram, isto é, a investigação de alguns pontos da releitura que Christine de Pizan faz da visão tradicional da mulher sujeitada a posturas e prerrogativas androcêntricas.

Nesse sentido, Le Livre de la Cité des Dames é não somente um audaz e penetrante questionamento, mas também uma percuciente resposta, baseada na inteligência e no bom senso, a uma vasta quantidade de textos misóginos revisitados 
pela autora, sendo que alguns dos piores ofensores são diretamente nomeados, como é o caso de Ovídio, Cecco d'Ascoli, Cícero e Catão, o Jovem (DE PIZAN, 20o6, p. 136139).

No capítulo IX do Livro Primeiro, que se intitula "Aqui trata de como Cristina cavou a terra, quer dizer, as questões que ela fez a Razão, e as respostas dessa última”, tais ofensores são anatomizados nas suas posturas misóginas. $\mathrm{O}$ entendimento é que os alicerces da cidade são buscados a partir das suas raízes misóginas, a exemplo de Ovídio, que é desmoralizado no seu discurso contra as mulheres por seu caráter sexual pervertido e dissoluto. Em Ovídio, Christine de Pizan, identifica uma das primeiras razões do rancor misógino, qual seja, a frustração no amor.

Fala, a seguir, da abominável misoginia de Cecco d'Ascolli e do livro De secretis mulieribus (Sobre o segredo das mulheres), de autoria duvidosa, escrito na linha de tratamento misógino da anatomia e fisiologia do organismo feminino, fundamentada pelos escritos de Aristóteles e Galeno, para tratar, principalmente, dos grandes defeitos e imperfeições corporais das mulheres desde a sua geração. Neste ponto da defesa, a Senhora Razão, demonstra um dos seus mais argutos silogismos para defender a paridade da mulher na criação divina e a redenção da queda de Eva pelos auspícios de sua messiânica Maria.

Mas Christine de Pizan escolhe diretamente como seu principal perturbador misógino o volumoso Les Lamentations de Matheolus (c. 1371), do já citado Jehan Le Fèvre, razão pela qual este artigo começa com esse livro para levantar os pontos de releitura do possível intertexto misógino de Christine de Pizan, além dos casos nominalmente referidos como no exemplo anterior. Outras fontes simpáticas à figura da mulher são referidas mais escassamente, excetuando-se o caso de Le Livre de Leesce, também de Jehan Le Fèvre, cuja referência, por ser muito pontual, merece um estudo à parte.

Logo no início do Primeiro Livro, Christine de Pizan, desprezando a autoridade de Les Lamentations de Matheolus, fica sensivelmente indignada com tantos renomados filósofos, poetas e oradores depreciadores das mulheres, principalmente, na sua malévola conclusão de que todo comportamento feminino é cheio de vícios, concluindo, ironicamente, que Deus só podia mesmo ter criado as mulheres como vis criaturas deformadas, reportando-se, evidentemente aqui, à tradição anatomista e fisiologista aristotélica, anteriormente comentada.

A partir desse ponto, Christine de Pizan recebe a visita de três senhoras soberanas e iluminadas, mais tarde identificadas como Razão, Retidão e Justiça (Figura 1). 


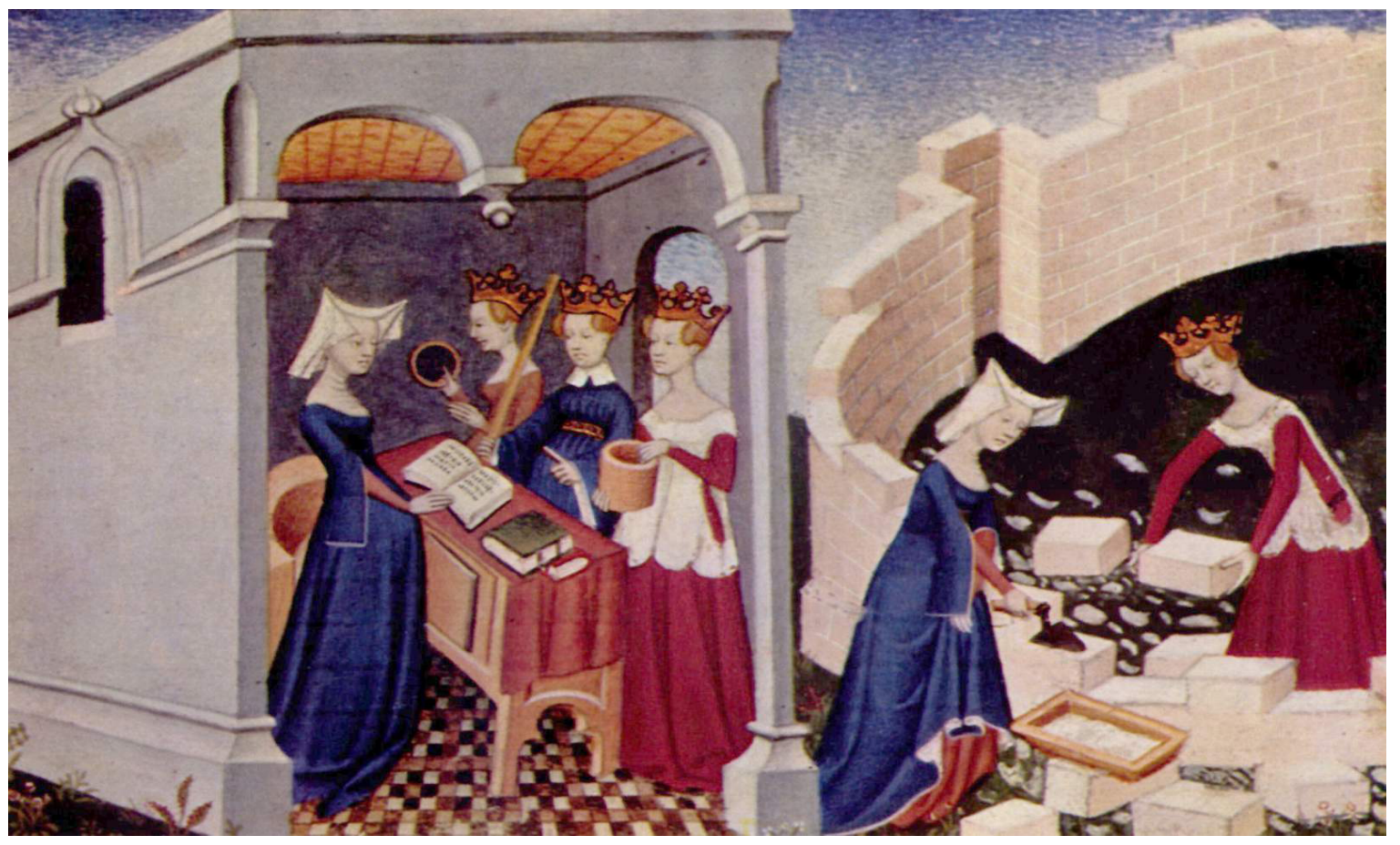

Figura 1: Deutsch: Miniatur aus der "Cité des Dames" der Christine de Pisan. Cite des Dames Master. (fl. 1400-1415). Bibliothèque nationale de France. Disponível em: <https:// commons.wikimedia.org/wiki/File:Meister_der_\%27Cit\%C3\%A9_des_Dames\%27_oo2. jpg >. Christine de Pizan e as três damas que participam da interlocução da criação alegórica de A Cidade das Damas (c. 1404). Acessado em 16/o8/20.

Um dos primeiros fundamentos de agudeza silogística para desarrazoar preconceitos misóginos é o da senhora Razão que argumenta que, mesmo o ataque dos homens às mulheres, com a finalidade de evitar os vícios e a conduta dissoluta delas, não é uma hipótese razoável para generalizações misóginas, porque seria como se condenasse o bom fogo porque queima e a benéfica água porque afoga, já que todas as coisas podem servir tanto para o bem como para o mal. Perguntando Christine de Pizan à Senhora Razão se esses homens fizeram bem, esta lhe responde sabiamente relativizando de forma extremamente racional sobre a moral do assunto.

Para tanto, toca a Senhora Razão em conceitos como generalizar por parcialidade, utilização das coisas boas para o mal, sempre tendo como referência o discurso dos homens sobre as mulheres, comprometido com preconceitos misóginos: "Mas (...) se eles tivessem procurado como levar os homens à razão, impedindo-os de cair na luxúria, censurando a vida e os modos de todas as mulheres cuja depravação fosse patente, então eu admitiria espontaneamente a excelência e a distinção de suas obras" (DE PIZAN, 2006, p. 132-133). Esse mesmo percuciente argumento já John Gower o havia empregado em seu livro A Lover's Confession / Confessio amantis (13861390) (Confissão de um amante), em favor da isenção da mulher na culpa metafórica de afogar ou atear fogo ao homem (GOWER, 1900, p. 355). 
Para a limpeza dos detritos sujos da misoginia, além da lembrança de inveterados livros misóginos da Antiguidade, a exemplo dos de Ovídio e de Juvenal, Christine de Pizan menciona o polêmico e virulento libelo misógino De secretis mulierum, um aberrante tratado ginecológico, espuriamente atribuído a Alberto Magno, de grande circulação no século XIII, que expõe, agravando os comentários da tradição de Aristóteles e de Santo Isidoro de Sevilha, os efeitos corruptos da menstruação.

Christine de Pizan comenta que o livro De secretis mulierum imputa à Natureza a vergonha por ter produzido o corpo da mulher tão deformado e corrompido por origem. Em resposta a Christine de Pizan, a senhora Razão faz uso de um dos mais altos pontos de arrazoamento e de aguda engenhosidade para enaltecer a mulher como a mais nobre criatura do plano divino da Criação. Para tanto, recorda que a mulher, ao ser formada da costela de Adão, foi a primeira a ser criada no Jardim do Éden, reproduzindo-se, aqui, o conhecido tópos da costela de Adão, bastante glosado no livro anônimo intitulado Dives and Pauper (1405-1410) (Dives e Pauper), a respeito do tema da paridade entre o homem e a mulher (DIVES AND PAUPER, 198o, p. 66).

A passagem, em que a Senhora Razão enaltece a origem da mulher, está repleta de pontos de releitura acerca da sua visão tradicional, a começar com a teoria de Aristóteles e de Galeno sobre a imperfeição anatômica e fisiológica do corpo feminino. A insistência de Christine de Pizan na controversa razão teológica da criação da mulher à imagem de Deus, rastreada em autoridades como Santo Agostinho em seu livro De Genesi ad litteram (401-416) (O sentido literal do Gênesis) (AUGUSTINE, 1982, p. 175-176), encontrou, entre outros, eco seminal em Graciano, em seu famoso Decretum (c.1140) (Decreto), um dos livros de referência central na Idade Média por sua compilação patrística (D’ALVERNY, 1977, p. 105-129).

Ainda sobre a argumentação de a mulher ser a mais nobre parte da criação terrestre, outro ponto de releitura de Christine de Pizan consiste na resposta antimisógina, de autoria anônima, ao livro intitulado Li Bestiaire d'Amour di Maistre Richard de Fournival e li Response du Bestiaire (c. 1250) (O bestiário do amor do mestre Ricardo de Fournival e a resposta do bestiário), de Richard de Fournival (DE FOURNIVAL, 1986, p. 41-43). Santo Ambrósio parece ser outro ponto dessa releitura, na passagem de seu livro De Paradiso (c.375) (Sobre o Paraíso), em que comenta, contrário ao tema do nascimento paradisíaco da mulher, sobre a superioridade do homem em termos de caráter e graça pela virtude (AMBROSE, 1896, p. 280). Por outro lado, aquela mesma consideração sobre a excelência original da mulher também é lembrada por Abelardo em sua Letter 6 (De auctoritate vel dignitate ordinis sanctimonialium), Carta 6 (Sobre a origem das freiras) (ABELARD, 1974, p. 129-175, p. 174).

A seguir, a Senhora Razão argumenta, lembrando a piedade e a caridade das mulheres devotas, contra a maledicência daqueles que dizem que as mulheres fazem da própria igreja um local para se exibirem em belos trajes, charmes e sedução (DE PIZAN, 2006, p. 141), razão pela qual as condena Jehan Le Fèvre em seu Les Lamentations de Matheolus (LE FÈVRE, 1892-1905, II. 1107-1242). Sobre o assunto, 
a Senhora Razão, elogiando virtudes naturalmente inerentes ao caráter feminino, desbarata a calúnia dos homens que dizem do vício da garrulice feminina praticado mesmo nos locais de recolhimento e oração, chamando a atenção para a dedicação à piedade cristã das mulheres: "Mas, se as mulheres já dão prova de devoção, de caridade é que nem precisa mencionar. Veja bem: quem faz visita aos doentes? Quem os reconforta? Quem presta socorro aos pobres? Quem vai aos hospitais? Quem enterra os mortos? Parece-me que se trata de obra das mulheres, e a via real que o próprio Deus nos ordena seguir" (DE PIZAN, 2006, p. 141-141).

Ainda no sentido derrogatório da mulher, no início do século XIII, um irreverente poema anônimo intitulado De Coniuge non ducenda (Contra o casamento) se destaca por falar da má esposa, que procura distantes abadias de peregrinação para os seus adulterinos propósitos (GAWAIN ON MARRIAGE, 1986, p. 81-82). O mesmo tema constitui legado para discussão de muitas obras misóginas subsequentes, a exemplo de Le Roman de la Rose (c.1275) (O romance da rosa), de Jean de Meun, que se refere à peregrinação das mulheres a lugares santos com intenções luxuriosas (DE MEUN, 1971, p. 230-231).

Seguindo no rol das tradicionais denegações da mulher, Christine de Pizan aborda o velho provérbio misógino latino, retomado por Geoffrey Chaucer em The Wife of Bath' Prologue (c.1390-1395) (Prólogo de a Esposa de Bath) (CHAUCER, 1985, p. 219-239), que diz que "Deus criou a mulher para chorar, falar e tear"(DE PIZAN, 2006, p. 142).

No tocante a esse trio misógino (chorar, falar e tear), a Senhora Razão protesta que Maria Madalena ganhou a especial graça de Deus em razão de suas lágrimas, enquanto que o grande pilar da Igreja, Santo Agostinho, havia se convertido pelas lágrimas de sua piedosa mãe (DE PIZAN, 2006, p. 142-143). Diz ela que, por compaixão das lágrimas femininas Cristo, ressuscitou Lázaro e que "A Sagrada Escritura conta vários outros milagres, cuja lista seria bastante longa, que Deus fez em favor das lágrimas de muitas mulheres; e o faz a cada dia" (DE PIZAN, 2006, p. 142-143).

Em referência ao falar feminino, comumente considerado na patrística medieval como falar abrasivo e virulento, quando não enfadonho e intolerável, Christine de Pizan desarrazoa a crítica feita à palavra da mulher com a menção de que Cristo escolheu exatamente uma mulher, Maria Madalena, para anunciar o mistério tão glorioso de sua Ressurreição. Em termos positivos, Christine de Pizan está, aqui, a reler e endossar, de forma apologética, não só a passagem da já citada Letter 6, de Abelardo, que confere às mulheres, testemunhas do Ressurreto, uma primazia sobre os Apóstolos (ABELARD, 1974, p. 129-130), mas também a passagem, em defesa da mesma causa, de The Book of Consolation and Advice / Liber consolationis et consilii) (c.1246) (O livro de consolação e conselho), de Albertano de Brescia (DE BRESCIA, 1873, p. 12-14), ambos antecessores de Christine de Pizan na defesa da mulher.

Em termos negativos, em seu diálogo demovedor da tradição misógina, relê e ressignifica, ainda, Christine de Pizan a tradicional depreciação masculinista da fala feminina que, adaptada de Ovídio em Les Lamentations de Matheolus, de Le Fèvre, comenta sobre a eternidade do sofrimento que as mulheres causam aos homens, pois 
os pássaros pararão de cantar e os grilos pararão no verão, também, antes que a mulher ache força para prender a sua língua, seja qual for o dano vindo das suas palavras (LE FÈVRE, 1892-1905, II. 177-250). A Senhora Razão, na mais meticulosa tradição dos exempla medievais, escolhe pontos-chaves dos Evangelhos para enaltecer piedosas e devocionais falas de fé de muitas mulheres citadas. E termina dizendo que "se Deus consentiu a palavra às mulheres, foi, na verdade, para que delas se sirvam. E, não se deve criticar nelas aquilo em que residem tantos benefícios e tão poucos males. Pois, raramente observou-se suas palavras provocarem algum dano" (DE PIZAN, 2006, p. 143-146).

Embora apoiando, de forma conservadora, a lei comum que avaliava a mulher com incapacidade para a o ensino em público, pregação e a jurisprudência, a Senhora Razão comenta que as mulheres não têm, por causa disso, um intelecto inferior. E; para exemplificar, maximamente, a superioridade intelectual da mulher, cita o caso de Nicostrata ou Carmenta, que deu à Itália leis e uma nova língua, isto é, o latim (DE PIZAN, 2006, p. 183-185), comentando que "um número considerável de ciências e técnicas importantes foram descobertas graças à inteligência e habilidade das mulheres, tanto nas ciências puras, como dão testemunho seus livros, quanto nas artes, demonstradas em obras manuais e elaboradas" (DE PIZAN, 2006, p. 183), Nicostrata encabeça uma lista bem investigada de mulheres famosas pela sua intelectualidade. Mais que digna posição, pois essa célebre mulher é a versão feminina da fundação da cidade de Roma, cuja importância chega ao máximo porque Nicostrata inventou mesmo o latim e deu nome de Itália à península que civilizou (DE PIZAN, 2006, p. 183-185).

No Livro Segundo, a Senhora Retidão substitui a Senhora Razão na interlocução demovedora da misoginia, Christine de Pizan lhe pergunta se os extremos depreciadores do matrimônio estão certos, citando Valério, o remetente de The Letter of Valerius to Ruffinus, against Marriage (c.118o) (A carta de Valerius a Ruffinus, contra o casamento), de Walter Map, e o próprio São Jerônimo que, em seu livro Adversus Jovinianum (c.393) (Contra Joviniano), aconselha mais a companhia de servos e de amigos que a ligação a uma esposa, que só conduz o marido à distração e ao desespero (JEROME, 1893, p. 412).

Ao que a senhora Retidão, dentre uma nobre lista de esposas notáveis por suas virtudes e bons feitos, responde com o exemplo de Xantipe, a digníssima consorte de Sócrates, intemerata companheira do marido até à morte (DE PIZAN, 2006, p. 238), apresentando um perfil da esposa do filósofo grego extremamente contrário àquele que dela faz São Jerônimo em seu Adversus Jovinianum (JEROME, 1893, p. 411).

Uma das mais preferidas discriminações da misoginia medieval criticadas e demolidas por Christine de Pizan, para a construção da sua virtuosíssima A Cidade das Damas, consiste na incriminação das mulheres por sua natural tendência e inclinação à não preservação da castidade, apenas oferecendo resistência quando o assédio sexual fosse deveras violento, fato esse desculpável no caso dos homens. A defesa da Senhora Retidão contra essa suposta licenciosidade feminina é feita no capítulo XLIV do Livro Segundo intitulado "Contra aqueles que dizem que mulheres 
querem ser violentadas são dados diversos exemplos, primeiramente, o de Lucrécia”, em que pode ser lido que os homens afirmam que as mulheres querem ser estupradas, que isso não as desagrada, mesmo quando se defendem gritando alto (DE PIZAN, 2006, p. 266-268).

Esse capítulo que fala da permissividade natural da mulher para ser assediada sexualmente revela, mais uma vez, a costumeira prerrogativa misógina dos critérios duplos, também condenada, entre inúmeras outras fontes, pelo livro The Southern Passion (de antes de 1290) (A paixão sulina), de autoria anônima (1927, est. 1923). Nessa sistemática dos chamados critérios duplo, não se permite à mulher o que é permitido ao homem e se permite ao homem o que não é permitido à mulher. Essa ambivalência de critérios é discutida, com grande força argumentativa em defesa da mulher, em Dives e Pauper, na parte que trata do adultério no homem e na mulher (DIVES AND PAUPER, 1980, p. 69). Conclui a Senhora Retidão que, a julgar por certos imperadores romanos e dignitários da Igreja, os homens têm muito pouco que gabar no que se refere ao quesito da constância. Nesse caso, exemplos de extrema perversidade são citados, inclusive na própria História Sagrada, como o do Apóstolo Judas Iscariotes (DE PIZAN, 2006, p. 275). E para concluir o tratamento retórico e estilístico, mas não menos ideológico no sentido de confronto demolidor da misoginia, enquanto reposítório de ideias e posturas antifemininas, Christine de Pizan, no Livro Terceiro da Cidade das Damas, coloca a Senhora Justiça a identificar as mais nobres ocupantes da sua cidade recém-concluída, estabelecendo a Virgem Maria como sua Imperatriz, seguida pelas venerandas mulheres bíblicas e pelas santas mártires do cristianismo, constantes e corajosas, encabeçadas por Santa Catarina da Alexandria que, sacrificada em 307, tornou-se figura pioneira e emblemática do martírio cristão em prol da devoção e da castidade.

Apesar de Christine terminar bem sucedidamente a construção de sua cidade com essa genuína apologia ao feminino irrepreensível, muita coisa de seu discurso desconstrutor ainda constitui tributo a ideais conservadores e latentes relativos à figura da mulher, principalmente, se for levado em contra que as três nobres senhoras dialogadas na obra são ainda formas retóricas e tropológicas que pertencem ao discurso masculino. Nesse sentido, ainda torna-se subliminarmente aceitável, no imaginário discursivo de Christine de Pizan, a colonialidade misógina das formulações paulinas de que a mulher só será redimida se se tornar a imagem do homem da qual foi criada. Somente com o passar dos tempos, com as transformações da sociedade, é que as nobres e hieráticas senhoras de A Cidade das Damas, irão perder a sua aura de excepcionalidade para dar lugar a pessoas-mulheres que, democraticamente, como sujeitos, deverão contar as suas próprias histórias. É, nesse sentido, que a voz de Christine de Pizan, ainda de origem ventríloca do universo masculino, apresenta as suas vozes femininas contra as derrogações das mulheres. 


\section{Referências}

ABELARD. Letter 6 (De auctoritate vel dignitate ordinis sanctimonialium). In: ABELARD. The Letters of Abelard and Heloise. Trad. C. K. S. Moncrieff. New York: Cooper Square Publishers, 1974, p. 129-175.

AMBROSE, St. De Paradiso. In: Opera. Ed. C. Schenkl. CSEL 32. 1. Vienna, 1896, p. 280.

AUGUSTINE, St. St Augustine: The Literal Meaning of Genesis (De Genesi ad litteram). Ancient Christian Writers, n. 42. Trad. J. H. Taylor, SJ, i. New York e Ramsey, NJ: Newman Press, 1982.

BOCCACCIO, Giovanni. Concerning Famous Women (De mulieribus claris). Trad. G. A. Guarino. London: Allen \& Unwin, 1964.

CHAUCER, Geoffrey. The Canterbury Tales. Trad. D. Wright. Oxford: Oxford University Press, 1985 .

D’ALVERNY, Marie-Therese. Comment les théologiens et les philosophes voient la femme. Cahiers de civilization médiévale, n. 20, Poitiers, 1977, p. 105-129.

DE BRESCIA, Albertano. Albertani Brixiensis Liber consolationis et consilii. Ed. T. Sundby. Chaucer Society, 2nd ser. 8. London, 1873.

DE FOURNIVAL, Richard. Response to The Bestiary of Love (Li Bestiaire d'Amour). In: Richard's Bestiary of Love and Response. Trad. J. Beer. Berkeley, Los Angeles e London: University of California Press, 1986, p. 41-43.

DELANY, Sheila. Medieval Literary Politics: Shapes of Ideology. Manchester: Manchester University Press, 1990.

DE MEUN, Jean. The Romance of the Rose by Guillaume de Lorris and Jean de Meun. Trad. C. Dahlberg. Princeton: Princeton University Press, 1971.

DE PIZAN, Christine. Oeuvres Poétiques. Ed. M. Roy. Paris: SATF, 1886-1891.

DE PIZAN, Christine. The Book of the City of Ladies. Trad. E. J. Richards. New York: Persea Books, 1982. 
DE PIZAN, Christine. A cidade das damas. Trad. L. E. de F. Calado. In: CALADO, Luciana Eleonora de Freitas, A cidade das damas: a construção da memória feminina no imaginário utópico de Christine de Pizan / Estudo e tradução. 2006. 371 páginas. Tese de Doutorado em Teoria da Literatura. Universidade Federal de Pernambuco, Recife, p. 113-358. Disponível em: <http://www.dominiopublico.gov.br/download/ texto cp059489.pdf.> Acessado em 05/o1/11.

DIVES AND PAUPER. Ed. P. Barnum. EETS, 228o, i. p.2. Oxford: 1980. Autor desconhecido.

FONSECA, Pedro Carlos Louzada. Mulher e Misoginia na visão dos Padres da Igreja e do seu legado medieval. Goiânia: PUC - Goiás, 2017.

FONSECA, Pedro Carlos Louzada. Introdução à misoginia medieval de Tertuliano a Chaucer: Estudo e leitura de textos fundamentais. New York: Peter Lang, 2020.

GAWAIN ON MARRIAGE: The Textual Tradition of the 'De Coniuge non Ducenda'. Anônimo. Ed. e trad. A. G. Rigg. Toronto: Pontifical Institute of Medieval Studies, 1986. Autor desconhecido.

GOTTLIEB, Beatrice. Feminism in the Fifteenth Century. In: KIRSHNER, J. e WEMPLE,

S. F. (Eds.). Women in the Medieval World: Essays in Honor of John H. Mundy. Oxford: Blackwell, 1985, p. 337-364.

GOWER, John. A Lover's Confession (Confessio amantis). In: GOWER, John. The English Works of John Gower. Ed G. C. Macaulay. EETS, ES 81, ii. London, 1900, p. 354-355.

JEROME, St. Against Jovinian (Adversus Jovinianum). In: The Principal Works of St Jerome. Trad. W. H. Fremantle. Select Library of Nicene and Post-Nicene Fathers, vi. Oxford: James Parker \& Co. e New York: Christian Literature Co., 1893, p. 346-416.

LE FÈVRE, Jehan. Les Lamentations de Matheolus et Le Livre de Leesce de Jehan le Fèvre. Ed. A.-G. Van Hamel. 2 vols. Paris: Bouillon, 1892-1905.

THE SOUTHERN PASSION. Ed. B. D. Brown. EETS, os 169. London: Oxford University Press, 1927. Autor desconhecido.

Recebido em 30/10/2020.

Aceito em 23/11/2020. 